\title{
Outcome Analysis of Cardiac Resynchronisation of Moderate to Severe Heart Failure in Relation to Blood Pressure Exercise Tolerance and Electrocardiography Changes
}

\author{
Brajendra Kumar ${ }^{1}$, Raj Kumar ${ }^{2}$ \\ ${ }^{1}$ Professor in Glocal Medical College Super Speciality Hospital and Research Center, Saharanpur, U.P, India \\ ${ }^{2}$ Assistant Professor in Glocal Medical College Super Speciality Hospital and Research Center, Saharanpur, U.P, India
}

\begin{abstract}
In approximately 30\% of patients with chronic heart failure the disease process not only depresses cardiac contractility but also affects the conduction pathways, causing delay in the onset of right/left ventricular systole. This dyssynchrony is apparent on the electrocardiogram (ECG) as a widened QRS of more than 120 msec. The finding of an intraventricular conduction delay has been associated with clinical instability and an increased risk of death in patients with heart failure. In recent studies it has been found that use of atrial-synchronized biventricular pacing can improve cardiac function, enhance functional capacity and the overall quality of life. Even though this method has received FDA (Food and Drug Administration) approval in 2001 as standard treatment, no long term studies have been conducted to know the outcome in these patients. Keeping in view the above facts / findings there is a need to study the outcome of cardiac resynchronization in patients with moderate to severe heart failure.
\end{abstract}

Keywords: Cardiac Resynchronisation, Chronic heart failure, Pacemaker,

\section{Introduction}

In approximately $30 \%$ of patients with chronic heart failure the disease process not only depresses cardiac contractility but also affects the conduction pathways by causing delay in the onset of right/left ventricular systole. This dyssynchrony is apparent on the electrocardiogram as a widened QRS of more than $120 \mathrm{msec}$. The finding of an intraventricular conduction delay has been associated with clinical instability and an increased risk of death in patients with heart failure.

In recent studies it has been found that use of atrialsynchronized biventricular pacing can improve cardiac function, enhance functional capacity and the quality of life.

Even though this method has received FDA approval in 2001 as standard treatment, no long term studies have been conducted to know the outcome in these patients. Keeping in view the above facts / findings there is a need to study the outcome of cardiac resynchronization in patients with moderate to severe heart failure in Indian subjects.

This study proposes to analyze outcomes in patients who have undergone atrial synchronized biventricular pacing at the Cardiology Centre (CHAF Bangalore).

The syndrome of congestive heart failure is responsible for substantial morbidity and mortality (19). Patients with heart failure have shortness of breath \& limited capacity for exercise, have high rates of hospitalizations and early deaths.

The primary mode of therapy of this syndrome is based on antagonism of neurohormonal pathways $(14,6,21)$ activated in the failing cardiovascular system. The drugs that antagonize these pathways decrease mortality and morbidity
$(14,6,21)$. Drug regimens comprising up to six classes of drugs have become the corner stone of therapy for heart failure. Mechanical support with left ventricular assist devices \& heart transplantation are reserved for the minority of patients who have severely decompensated heart failure (9). Despite these therapeutic advances, it is generally accepted that current therapies do not adequately address the clinical needs of patients with heart failure and additional strategies are being developed.

Approximately $30 \%$ of patients with cardiomyopathy have intraventricular conduction delay leading to loss of coordination of ventricular contraction (12). This dyssynchronous pattern of ventricular contraction is believed to contribute to the pathophysiology of heart failure, reducing already diminished contractile reserve of heart (10). Specifically dyssynchronous contraction exacerbates inefficient use of energy by the heart in patients with conduction system delays, indicated by a widened QRS interval on the surface electrocardiogram. Consequently such cases have worse clinical outcome than those with normal QRS intervals (12). Accordingly the idea that cardiac pacing technology might be used to restore the synchrony of ventricular contraction has been the subject of interest, for over a decade.

A recent multicentric study [MIRACLE TRIAL (22)] demonstrated improvement in symptoms and exercise capacity and reduced rate of hospitalizations for heart failure over a six month period.

The findings confirm the results of earlier trials\& pathophysiological studies $(10,18)$. Even though the results are exciting there is a need for studies to assess the long term outcome of cardiac re-synchronization. 


\section{International Journal of Science and Research (IJSR) \\ ISSN (Online): 2319-7064 \\ Index Copernicus Value (2013): 6.14 | Impact Factor (2014): 5.611}

\section{Material \&Methods}

Patients of Command Hospital Air Force (CHAF), Bangalore who have under gone cardiac resynchronization for moderate to severe heart failure were included in the trial. This was a hospital based study involving 15 patients.

This was a hospital based study involving patients who met inclusion and exclusion criteria. Inclusion criteria were moderate or severe (NYHA class III or IV) chronic heart failure due to either ischemic or nonischemic cardiomyopathy, left ventricular ejection fraction of 35 percent or less, QRS interval of $130 \mathrm{msec}$ or more, a sixminute walking distance of $450 \mathrm{~m}$ or less, patients must have received all appropriate treatments for heart failure, which included a diuretic, an ACE-inhibitor or an ARB, and (usually) digitalis and a beta-blocker. The doses of these background medications were stable for at least one month, except for doses of the beta-blocker (which were stable for three months).

Patients were excluded if they had a pacemaker, cardioverter-defibrillator,contraindication to cardiac pacing, cardiac or cerebral ischemic event within the previous three months, or if they had had an atrial arrhythmia within the previous month. Patients with any other end organ failure were excluded, patients with diabetes and hypertension were not excluded. In addition, patients were excluded if they had a systolic blood pressure of more than 170 or less than 80 $\mathrm{mm} \mathrm{Hg}$, a heart rate of more than 140 beats per minute, a serum creatinine level of more than $3.0 \mathrm{mg}$ per deciliter $(265$ $\mu$ mol per liter), or serum aminotransferase levels more than three times the upper limit of normal. Data collection was done by clinical history taking, examination \& investigations

Over one year follow-up, statistically significant improvement in 6 minute walking ability, ejection fraction on 2-D echo and reduction in total hospital admissions were noticed (table 01, 04 \& figure 06). Even though changes in ECG were also noticed, the p-value was not statistically significant ( table 01, 05).

\section{Discussion}

In this study groupfifteen patients underwent cardiac resynchronisation between Jan 2003 and May 2004 at CHAF, Bangalore. Of the fifteen patients 14 (93\%) patients were males and $01(07 \%)$ patient was female.

The mean age of the study group was 54.06 years (range 37 - 65). $10(67 \%)$ patients were between 50 to $60 \mathrm{yrs}$ of age, $3(20 \%)$ were below 50 yrs of age and $2(13 \%)$ were more than $60 \mathrm{yrs}$ of age.

Out fifteen patients almost $2 / 3^{\text {rd }}$ had co-morbidities in the form of type 2 diabetes mellitus, hypertension or combination of the two as shown in figure 03 . Of these $1 / 3^{\text {rd }}$ of the patients had no co-morbidities. Patients with any other end organ failure were excluded from study. Diabetes constituted for $34 \%$ comorbidities statistically no significant change when compared large group trials (13). and details were recorded as per the protocol attached as annexure. The data collected was subjected to statistical analysis for determining the significance of the results. Clearance was been obtained from the Hospital Ethical Committee. The institutional review board approved the study protocol, and all patients gave written informed consent.

Detailed clinical history, examination, routine investigations and the following three special investigations

a) Six minute walk test

b) $2 \mathrm{D}$ echocardiography

c) 12 lead electrocardiogram

All eligible patients have underwent CRT. CRT using Guidant CRT devices and multi-sitepacing done. Three pacing leads, a standard right atrial lead, a standard right ventricular lead, and a specialized left ventricular lead which was placed into a distal cardiac vein through the coronary sinus using a guiding catheter. Patients who had undergone successful implantation (CRT device) were followed up 3 monthly for one year $\&$ the following tests were done:-

a) Six minute walk test

b) $2 \mathrm{D}$ echocardiography

c) 12 lead electrocardiogram

\section{Results}

Table 1: Final Out Come

\begin{tabular}{|c|c|c|}
\hline VARIABLE & t - VALUE & $\mathbf{p}$-VALUE \\
\hline ECG CHANGES & 1.89 & $\mathrm{p}=0.091$ \\
\hline SIX MIN WALK & 7.371 & $\mathrm{p}<0.001$ \\
\hline EF CHANGES & 13.18 & $\mathrm{p}<0.001$ \\
\hline
\end{tabular}

Three patients died during follow up with in first three months of cardiac resynchronization. No statistically significant variation noticed between this study and large trials conducted $(22,04,13)$. One patient $(6.7 \%)$ was lost to follow up after three months of cardiac resynchronisation is same as other trials $(22,13)$.

Our results indicated that the use of cardiac resynchronization improved major clinical outcomes in patients with a prolonged QRS interval and advanced, symptomatic heart failure as a result of moderate to- severe left ventricular systolic dysfunction.

Patients showed improvement in cardiac ejection fraction (figure 04, table 01, 02, 08), after CRT. At six months the results are consistent with short-term studies (22), on further follow up noticed to have further improvement by 5 to $6 \%$ increase in ejection fraction. Six minute walking distance consistently improved over a period of one year (figure 05, table $01,03,07$ ), which has shown over $100 \%$ improvement, once again consistent with short-term studies $(18,22)$

Even though ECG changes were clinically significant on case-to-case basis and at $3 \& 6$ months, not shown to have statistically significant changes at the end of one year (figure 07, table 01, 05, 06). Short-term changes were consistent with short-term trials $(18,22)$. 


\section{International Journal of Science and Research (IJSR) \\ ISSN (Online): 2319-7064 \\ Index Copernicus Value (2013): 6.14 | Impact Factor (2014): 5.611}

Significant finding that needs further evaluation is significant reduction in number of hospital admissions by more than $50 \%$ in disease related admissions (figure 06 , table 01, 04).

There was no device implantation failure in the subjects involved in this study. Most of the short term studies had 1 to $2 \%$ implantation related complications $(18,22,13)$. May be due to advancement of procedural techniques and small sample size this variation was noticed.

There were three deaths during first 03 months of study. No deaths took place after three months until one year of follow-up was completed. One case was lost to follow up due to domestic problems.

Our results extend those of earlier short-term studies $(18,04,13)$ that evaluated the effects of CRT on exercise tolerance, decreased hospital admission rate, in a population with advanced heart failure with widened QRS interval.

Therapy improves most major factors that affect the quality of life. The clinical efficacy of CRT with a pacemaker is noteworthy, since the therapy was delivered in conjunction with the best evidence-based pharmacological therapy for heart failure.

The pacemaker is associated with a reduction in hospitalizations and symptoms and improved exercise tolerance and quality of life.

The decision of which of these two therapeutic options is appropriate for a particular setting is best determined on an individual basis by patients and their Cardiologists.

Table 6: Over All Progression of ECG QRS Duration Of Eleven Patients Over One Year*

\begin{tabular}{|c|c|c|c|c|c|}
\hline Patient no & ECG at enrolment & ECG at three months & ECG at 6 Months & ECG at 9 MONTHS & ECG at 1 year \\
\hline 1 & QRS 0.16sec & QRS 0.12SEC & QRS 0.12SEC & QRS 0.14SEC & QRS 0.12SEC \\
\hline 2 & QRS 0.18SEC & QRS 0.14SEC & QRS 0.12SEC & QRS 0.13SEC & QRS 0.12 SEC \\
\hline 3 & QRS 0.16SEC & QRS 0.12 SEC & QRS 0.14 SEC & QRS 0.14SEC & QRS 0.12 SEC \\
\hline 5 & QRS 0.16 SEC & QRS 0.14SEC & QRS 0.14SEC & QRS 0.12SEC & QRS 0.12SEC \\
\hline 6 & QRS 0.19 SEC & QRS 0.14SEC & QRS 0.15SEC & QRS 0.13SEC & QRS 0.14SEC \\
\hline 8 & QRS 0.15SEC & QRS 0.14SEC & QRS 0.14 SEC & QRS 0.13SEC & QRS 0.13SEC \\
\hline 9 & QRS 0.16SEC & QRS 0.16 SEC & QRS 0.15SEC & QRS 0.13SEC & QRS 0.13 SEC \\
\hline 10 & QRS 0.18SEC & QRS 0.16 SEC & QRS 0.16SEC & QRS 0.14SEC & QRS 0.12SEC \\
\hline 12 & QRS 0.188SEC & QRS 0.17SEC & QRS 0.18SEC & QRS 0.144SEC & QRS 0.134SEC \\
\hline 14 & QRS 0.14SEC & QRS 0.13SEC & QRS 0.12SEC & QRS 0.10SEC & QRS 0.10SEC \\
\hline 15 & QRS 0.16SEC & QRS 0.14SEC & QRS 0.12SEC & QRS 0.11SEC & QRS 0.10SEC \\
\hline \multicolumn{7}{|c}{$*$ Patient number 4, 7, 11 died with in first three months, patient no 13 lost to follow up } \\
\hline
\end{tabular}

Volume 4 Issue 12, December 2015 www.ijsr.net

\section{Time}

\begin{tabular}{|c|c|c|c|}
\hline & MEAN & SD & MEDIAN \\
\hline BASE $(\mathrm{n}=15)$ & 29.29 & 45.71 & 17.5 \\
\hline 3 Month $(\mathrm{n}=12)$ & 14.27 & 1.62 & 14 \\
\hline 6 Month $(\mathrm{n}=11)$ & 14 & 2.06 & 14 \\
\hline 9 Month $(\mathrm{n}=11)$ & 25.9 & 41.52 & 13 \\
\hline 12 Month $(\mathrm{n}=11)$ & 24.2 & 38.6 & 12 \\
\hline
\end{tabular}

Table 2: Variation in the Lvef Values Over Time****

Table 3: Variation In The 6 Minute Walk Values Over Time****

\begin{tabular}{|c|c|c|c|}
\hline & MEAN & SD & MEDIAN \\
\hline BASE $(n=13)^{*}$ & 178.08 & 72.1 & 200 \\
\hline 3 Month $(\mathrm{n}=12) * *$ & 260 & 61.16 & 200 \\
\hline 6 Month $(\mathrm{n}=11)^{* * *}$ & 343.18 & 81.95 & 320 \\
\hline 9 Month $(\mathrm{n}=11)$ & 420.5 & 142.37 & 372.5 \\
\hline 12 Month $(\mathrm{n}=11)$ & 541.6 & 164.08 & 480 \\
\hline \multicolumn{4}{|c|}{$\begin{array}{l}\text { *Two were unable to walk ** Three died with in first three } \\
\text { months } * * * \text { One lost to follow-up }\end{array}$} \\
\hline
\end{tabular}

Table 5: Variation in the ECG Values (QRS Duration) Over 


\section{International Journal of Science and Research (IJSR) \\ ISSN (Online): 2319-7064 \\ Index Copernicus Value (2013): 6.14 | Impact Factor (2014): 5.611}

Table 7: Over all Progression of Six Minute Walking Distance Of Eleven Patients Over One Year *

\begin{tabular}{|c|c|c|c|c|c|}
\hline Patient No & $\begin{array}{c}\text { Six mins walk at } \\
\text { enrolment }\end{array}$ & $\begin{array}{c}\text { Six mins walk test } \\
\text { at 3 months }\end{array}$ & $\begin{array}{c}\text { Six mins walk test at 6 } \\
\text { months }\end{array}$ & $\begin{array}{c}\text { Six mins walk test at 9 } \\
\text { months }\end{array}$ & $\begin{array}{c}\text { Six mins walk test } \\
\text { at } 1 \text { year }\end{array}$ \\
\hline 1 & 50 MTR & $200 \mathrm{MTR}$ & $300 \mathrm{MTR}$ & $350 \mathrm{MTR}$ & $450 \mathrm{mtr}$ \\
\hline 2 & $200 \mathrm{MTR}$ & $250 \mathrm{MTR}$ & $325 \mathrm{MTR}$ & $380 \mathrm{MTR}$ & $500 \mathrm{MTR}$ \\
\hline 3 & $150 \mathrm{MTR}$ & $220 \mathrm{MTR}$ & $280 \mathrm{MTR}$ & $365 \mathrm{MTR}$ & $800 \mathrm{MTR}$ \\
\hline 5 & $160 \mathrm{MTR}$ & $200 \mathrm{MTR}$ & $290 \mathrm{MTR}$ & $400 \mathrm{MTR}$ & $620 \mathrm{MTR}$ \\
\hline 6 & $75 \mathrm{MTR}$ & $150 \mathrm{MTR}$ & $300 \mathrm{MTR}$ & $320 \mathrm{MTR}$ & $400 \mathrm{MTR}$ \\
\hline 8 & $200 \mathrm{MTR}$ & $250 \mathrm{MTR}$ & $275 \mathrm{MTR}$ & $300 \mathrm{MTR}$ & $350 \mathrm{MTR}$ \\
\hline 9 & $250 \mathrm{MTR}$ & $350 \mathrm{MTR}$ & $500 \mathrm{MTR}$ & $750 \mathrm{MTR}$ & $800 \mathrm{MTR}$ \\
\hline 10 & $180 \mathrm{MTR}$ & $250 \mathrm{MTR}$ & $350 \mathrm{MTR}$ & $400 \mathrm{MTR}$ & $500 \mathrm{MTR}$ \\
\hline 12 & $200 \mathrm{MTR}$ & $300 \mathrm{MTR}$ & $320 \mathrm{MTR}$ & $340 \mathrm{MTR}$ & $460 \mathrm{MTR}$ \\
\hline 14 & $250 \mathrm{MTR}$ & $300 \mathrm{MTR}$ & $350 \mathrm{MTR}$ & $400 \mathrm{MTR}$ & $450 \mathrm{MTR}$ \\
\hline 15 & $300 \mathrm{MTR}$ & $350 \mathrm{MTR}$ & $500 \mathrm{MTR}$ & $600 \mathrm{MTR}$ & $700 \mathrm{MTR}$ \\
\hline
\end{tabular}

Table 8: Over All Progression of Ejection Fraction of Eleven Patients Over One Year *

\begin{tabular}{|c|c|c|c|c|c|}
\hline Patient No & $\begin{array}{c}\text { EF at } \\
\text { enrolment }\end{array}$ & $\begin{array}{c}\text { EF at } 3 \\
\text { months }\end{array}$ & $\begin{array}{c}\text { EF at } 6 \\
\text { Months }\end{array}$ & $\begin{array}{c}\text { EF at } 9 \\
\text { Months }\end{array}$ & $\begin{array}{c}\text { EF at } 1 \\
\text { year }\end{array}$ \\
\hline 1 & $10 \%$ & $16 \%$ & $18 \%$ & $20 \%$ & $23 \%$ \\
\hline 2 & $18 \%$ & $20 \%$ & $22 \%$ & $23 \%$ & $26 \%$ \\
\hline 3 & $22 \%$ & $25 \%$ & $25 \%$ & $30 \%$ & $38 \%$ \\
\hline 5 & $24 \%$ & $28 \%$ & $29 \%$ & $31 \%$ & $35 \%$ \\
\hline 6 & $15 \%$ & $16 \%$ & $18 \%$ & $21 \%$ & $28 \%$ \\
\hline 8 & $25 \%$ & $26 \%$ & $28 \%$ & $30 \%$ & $34 \%$ \\
\hline 9 & $28 \%$ & $30 \%$ & $33 \%$ & $35 \%$ & $37 \%$ \\
\hline 10 & $30 \%$ & $34 \%$ & $36 \%$ & $38 \%$ & $42 \%$ \\
\hline 12 & $23 \%$ & $26 \%$ & $29 \%$ & $38 \%$ & $38 \%$ \\
\hline 14 & $23 \%$ & $26 \%$ & $29 \%$ & $30 \%$ & $32 \%$ \\
\hline 15 & $30 \%$ & $32 \%$ & $33 \%$ & $36 \%$ & $41 \%$ \\
\hline$*$
\end{tabular}

\section{Conclusion}

Outcome analysis of the study shows that cardiac resynchronisation therapy improves 6 minute walking distance and left ventricular ejection fraction. It also reduces the number of hospital admission in patients of moderate to severe heart failure. Device related complications are not significant.

A larger study over a longer duration is required in Indian population. Some of the issues that need to be studied are

(a) Prognostic identification of subjects

(b) Quantification \& etiological differentiation of survival benefits

(c) Early, intermediate \& long term complication

(d) Causes of death

\section{References}

[1] ACC/AHA Guidelines for Implantation of Cardiac Pacemakers and Arrhythmia Devices. A Report of the American College of Cardiology/American Heart Association Task Force on Practice Guidelines (Committee on Pacemaker Implantation) JACC 1998: 31: 1175-209.

[2] Angelo Auricchio, MD, PhD; Christoph Stellbrink, MD; Michael Block, MD; Stefan Sack, MD; Jürgen Vogt, MD; Patricia Bakker, MD, et al. The effect of pacing chamber and atrio-ventricular delay on acute systolic function of paced patients with congestive heart failure. Circulation, 1999; 99: 2993-3001.

[3] Auricchio A, Stellbrink C, Sack S, Block M, Vogt J, Bakker $\mathrm{P}$, et al. The Pacing Therapies for Congestive Heart Failure (PATH-CHF) Study: Rationale, design, and end points of a prospective randomized multicenter study. Am J Cardiol 999;83:Suppl 5B:130D-5D.

[4] Auricchio A, Stellbrink C, Sack S, Block M, Vogt J, Bakker P,Mortensen P, Klein H, for the 'PATH-CHF' Study Group. The Pacing Therapy for Congestive Heart Failure (PATH CHF) study: rationale,design and endpoints of a prospective randomized multicentre study. Am J Cardiol 1999; 83 (suppl): 130D-135D.

[5] Berry C, Murdoch DR, Murray, JJ. Economics of chronic heart failure. Eur J Heart Fail. 2001; 3: 283-91.

[6] Bertram Pitt, M.D., Faiez Zannad, M.D., Willem J. Remme, M.D., Robert Cody, M.D., Alain Castaigne, M.D., Alfonso Perez, M.D., et al. The effect of Spironolactone on morbidity and mortality in patients with severe heart failure. N Eng J Med 1999; 341:70917.

[7] Blanc JJ, Etienne Y, Gilard M, Mansourati J, Munier S, Boschat J, Benditt DG, Lurie KG. Evaluation of different ventricular pacing sites in patients with severe heart failure. Results of an acute hemodynamic study. Circulation 1997; 96: 3273-3277.

[8] Cazeau S, Leclercq C, Lavergne T, et al. Effects of multisite biventricular pacing in patients with heart failure and intraventricular conduction delay. N Engl J Med 2001; 344: 873-880.

\section{Volume 4 Issue 12, December 2015}




\section{International Journal of Science and Research (IJSR) \\ ISSN (Online): 2319-7064 \\ Index Copernicus Value (2013): 6.14 | Impact Factor (2014): 5.611}

[9] Eric A. Rose, M.D., Annetine C. Gelijns, Ph.D., Alan J. Moskowitz, M.D., Daniel F. Heitjan, Ph.D., Lynne W. Stevenson, M.D., Walter Dembitsky, M.D., et al. Longterm use of a left ventricular assist device for end-stage heart failure. N Eng J Med 2001; 345:1435-43.

[10] Gregory S. Nelson, PhD; Ronald D. Berger, MD, PhD; Barry J. Fetics, MSE; Maurice Talbot, RN; Julio C. Spinelli, PhD; Joshua M. Hare, MD; David A. Kass, MD. Left ventricular or biventricular pacing improves cardiac function at diminished energy cost in patients with dilated cardiomyopathy and left bundle-branch block. Circulation 2000; 102:3053-59.

[11] K. MacIntyre, MBChB; S. Capewell, MD, FRCPE; S. Stewart, PhD, NFESC; J.W.T. Chalmers, FFPHM; J. Boyd, BSc; A. Finlayson, BSc; et al. Evidence of improving prognosis in heart failure: trends in case fatality in 66,547 patients hospitalized between 1986 and 1995. Circulation. 2000; 102:1126-31.

[12]Leclerq C, Kass DA. Retiming the failing heart: principles and current clinical status of cardiac resynchronization. J Am Coll Cardiol 2002; 39:194201.

[13] Michael R. Bristow, M.D., Leslie A. Saxon, M.D., John Boehmer, M.D., Steven Krueger, M.D., David A. Kass, M.D., Teresa De Marco, M.D., et al. CardiacResynchronization Therapy with or without an Implantable Defibrillator in Advanced Chronic Heart Failure. N Engl J Med 2004;350:2140-50.

[14] Milton Packer, M.D., Andrew J.S. Coats, M.D., Michael B. Fowler, M.D., Hugo A. Katus, M.D., Henry Krum, M.B., B.S., Ph.D., Paul Mohacsi, M.D., et al. Effect of carvedilol on survival in chronic heart failure. N Eng $\mathrm{J}$ Med 2001;344:1651-8.

[15] Nelson GS, Berger RD, Fetics BJ, Talbot M, Spinelli JC, Hare JM, Kass DA. Left ventricular or biventricular pacing improves cardiac function at diminished energy cost in patients with dilated cardiomyopathy and left bundlebranch block. Circulation. 2000; 102:3053-9.

[16] Petrie M, McMurray J. Changes in notions about heart failure. Lancet 2001; 358: 432-34

[17] S. Stewart1, K. MacIntyre1, M. M. C. MacLeod, A. E. M. Bailey, S. Capewell and J. J. V. McMurray. Trends in hospitalization for heart failure in Scotland, 19901996. An epidemic that has reached its peak? Eur Heart J. 2001; 3: 209-17.

[18] Serge Cazeau, M.D., Christophe Leclercq, M.D., Thomas Lavergne, M.D., Stuart Walker, M.D., Chetan Varma, M.D., Cecilia Linde, M.D., et al. Effects of multisite biventricular pacing in patients with heart failure and intraventricular condution delay. $\mathrm{N}$ Engl $\mathrm{J}$ Med 2001;344:873-880.

[19] Sharon A. Hunt, David W. Baker, Marshall H. Chin, Michael P. Cinquegrani, Arthur M. Feldmanmd, Gary S. Francis, et al. ACC/AHA guidelines for the evaluation and management of chronic heart failure in adult: Circulation 2001; 104: 2996-3007

[20] Stewart S, MacIntyre K, Hole DJ, Capewell S, McMurray JJ. More 'malignant' than cancer? Five-year survival following a first admission for heart failure. Eur J Heart Fail. 2001 ;3(3):315-22.

[21]The SOLVD Investigators. Effect of Enalapril on survival in patients with reduced left ventricular ejection fractions. N Eng J Med 1991;325:293-302.
[22] William T. Abraham, M.D., Westby G. Fisher, M.D. Andrew L. Smith, M.D., David B. Delurgio, M.D., Angel R. Leon, M.D., Evan Loh, M.D., et al. Cardiac resynchronization in chronic heart failure. $\mathrm{N}$ Engl J Med 2002; 346:1845-53

\section{Volume 4 Issue 12, December 2015}

